\title{
Plant-Derived Compounds for Wound Healing- A Review
}

\author{
Rex Jeya Rajkumar S ${ }^{1}$, MSA Muthukumar Nadar ${ }^{1}$ and Paulraj Mosae Selvakumar ${ }^{2 *}$ \\ ${ }^{1}$ Department of Biosciences and Technology, Karunya University, India \\ ${ }^{2}$ Department of Chemistry, Karunya University, India
}

Submission: December 22, 2017 Published: January 11, 2018

*Corresponding author: Paulraj Mosae Selvakumar, Department of Chemistry, Karunya University, Tamil Nadu, India, Email: pmosae@gmail.com

\begin{abstract}
Wounds are the result of damages or injuries that disturb the normal structure of the skin tissue. Wound healing is a natural but a protracted and complex process of tissue repairing, regenerating, and remodelling in response to wounding injury. Various plant products have been used in the treatment of wounds over the years. Compounds that are derived from medicinal plants need to be identified, screened and analyzed for its antimicrobial, anti-oxidant, and wound healing activity. Wound healing phytochemical compounds fights infection, promotes blood clotting, and accelerate the healing process. Numerous phytochemical compounds have been identified and synthesized from medicinal plants that have unique properties associated with the mechanism of wound healing. This review focus on the plant-derived phytochemical compounds that promote wound healing process.
\end{abstract}

Keywords: Phytochemicals; Compounds; Wound; Wound Healing; Medicinal Plants

Abbreviations: CAM: Chick Chorioallantoic Membrane; JNK: Jun N-Terminal Kinases; FAK: Focal Adhesion Kinases; Erk: Extracellular SignalRegulated Kinases

Introduction

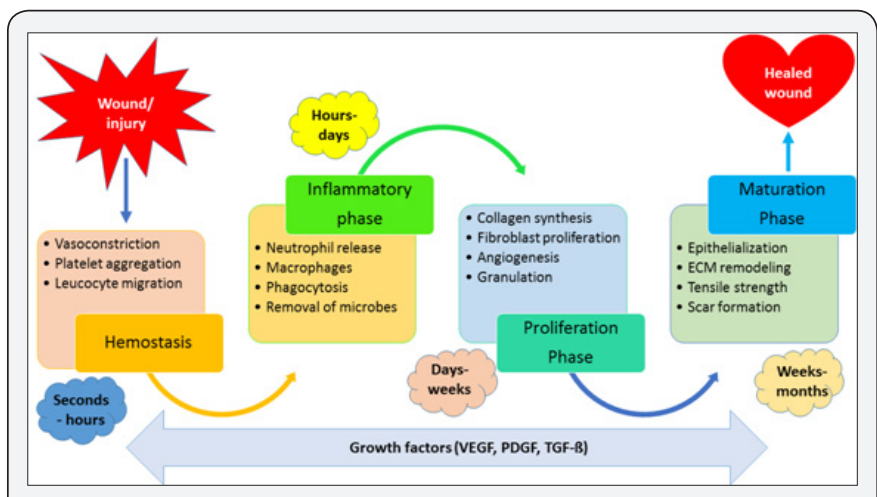

Figure 1: Phases of wound healing.

Wound healing is a natural but a systematic and complex process which involves three different phases i.e. inflammatory phase, proliferative phase and maturation phase $[1,2]$. Wounds affect the patients quality of life by high cost for the treatment [3]. Medicinal plants have been used worldwide, as traditional treatments for wound healing. The plant-derived compounds from medicinal plants have proven to have wound healing properties, of which many have been used to start the development of new inputs for the pharmaceutical industry. Traditional medicinal plants have a strong perspective on the treatment and management of wounds. The therapeutic value of these plant-derived compounds that produce certain physiological action on the human body [4]. These compounds belong to the families like alkaloids, essential oils, flavonoids, tannins, terpenoids, saponins, and phenolics (Figure 1) [5]. Numerous studies in the literature detailed the activities and effects of plant-derived compounds with anti-microbial, antioxidant properties that promote faster-wound healing and skin regeneration [6-12]. In this chapter, we review the various types of plant-derived phytochemical compound that promotes wound healing process (Table 1).

Table 1: Plant-derived phytochemical compounds with wound healing properties.

\begin{tabular}{|c|c|c|}
\hline S. No & Phytochemical Class & Compounds \\
\hline 1 & Alkaloid & Berberine \\
\hline 2 & Cardenolides & Calotropin \\
\hline 3 & Coumarin & Cleomiscosin A, B, C and D \\
\hline 4 & Cyanogenic glucoside & Acalyphin \\
\hline
\end{tabular}




\section{Organic and Medicinal Chemistry International Journal}

\begin{tabular}{|c|c|c|}
\hline 5 & Flavonoid & Kaempferol, Quercetin \\
\hline 6 & Glycoside & Morindin, Rutin \\
\hline 7 & Polyphenol & Curcumin, Chlorogenic acid, Ferulic acid, Caffeic acid \\
\hline 8 & Sterol & ampesterol, ß-sitosterol and Stigmasterol \\
\hline 9 & Tannins & Gallic acid, Tannic acid \\
\hline 10 & Terpenes & $\begin{array}{c}\text { Asiaticoside, Lupeol, Asiatic acid, Jasminol, Madecassic acid, Cleomeolide, } \\
\text { Scabertopin, Salograviolide A, Ursolic acid }\end{array}$ \\
\hline
\end{tabular}

\section{Plant-derived wound healing compounds}

Asiaticoside: A triterpene glycoside compound Asiaticoside, isolated from Centella asiatica, is commonly known for its significant wound healing properties that have been studied in normal as well as diabetic wound healing. A topical application of $0.4 \%$ solution of asiaticoside over the wound of streptozotocin-induced diabetic rats increased the tensile strength, hydroxyproline content, protein content and epithelialization thereby facilitating the wound healing [13]. In guinea pig, $0.2 \%$ solution of asiaticoside was applied topically which produced an increase in hydroxyproline, tensile strength and quick healing. Asiaticoside promoted angiogenesis in the CAM (chick chorioallantoic membrane) model at $40 \mu \mathrm{g} /$ disk concentration. Enhanced wound healing activity was achieved by Asiaticoside has been attributed to Angiogenesis, collagen formation increased remodelling of the collagen matrix and stimulation of glycosaminoglycan synthesis in a rat wound chamber model $[14,15]$. Since antioxidants play an important role in the wound healing process, the effects of asiaticoside on the levels of antioxidants in the wound were reported in many researchers to explore the possible mechanism of asiaticoside in wound healing (Figure 2).

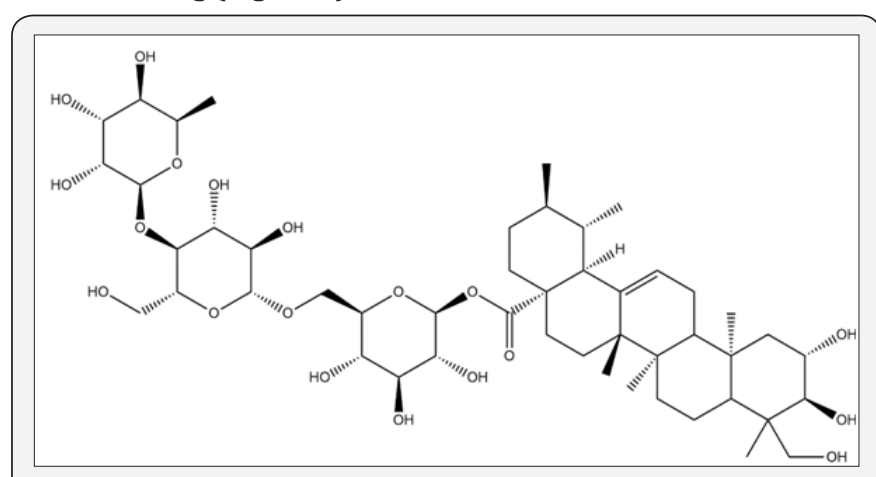

Figure 2 : Structure of Asiaticoside.

Topical application of Asiaticoside (0.2\%) in cutaneous wounds in rats led to increased enzymatic and non-enzymatic antioxidants such as glutathione peroxidase, superoxide dismutase, catalase, vitamin $\mathrm{E}$ and Vitamin $\mathrm{C}$ (ascorbic acid) in newly formed tissues and decrease in lipid peroxide levels. Studies revealed that asiaticoside enhanced induction of antioxidant levels at an initial phase of wound healing. All these reports indicate that asiaticoside exhibits significant wound healing activity in normal as well as delayed healing models [16].
Curcumin: A phenolic compound, Curcumin, isolated from Curcuma longa Linn $[17,18]$ known for its various biological and therapeutic properties reported possessing significant wound healing, antioxidant, anti-inflammatory, antimutagenic, anticarcinogenic, anti-infective and anticoagulant effects $[17,19]$. The wound-healing potential of curcumin is attributed to its anti-inflammatory, anti-oxidant and anti-infectious properties and also due to the inhibition of STAT, TNF- $\alpha$, cyclin D1, COX-2, NFkB, IL (-1b, -6, -8 ) expressions, and down-regulation of MMP8 expression [20]. Numerous studies demonstrated its diabetic wound healing of Curcumin (Figure 3) [21]. Curcumin is involved in collagen deposition, tissue remodelling, increased in fibroblast proliferation, granulation tissue formation and vascular density [17]. Curcumin is reported to have a strong antibacterial activity of curcumin is due to its action against the bacterial membrane [22]. Curcumin inhibited the growth of dangerous pathogens like methicillin-resistant Staphylococcus aureus (MRSA) [23], P. gingivalis, P. intermedia, F. nucleatum, T. denticola [24], B. cereus, E. coli [25], S. mutants, E. faecalis, P. aeruginosa and B. subtilis [22].

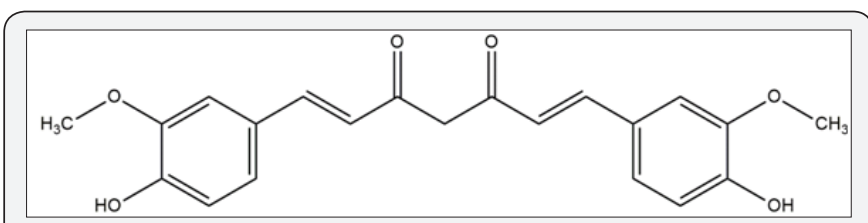

Figure 3 : Structure of Curcumin.

Chlorogenic acid: A polyphenolic compound, Chlorogenic acid is one of the most abundant polyphenols in the human diet [26]. Most of the heat-clearing Chinese medicines contain chlorogenic acid, which is also commonly used as the characteristic marker of quality control for traditional Chinese medicines because of its antibacterial activities [27]. As for other polyphenols, data obtained from in vivo and in vitro experiments showed that chlorogenic acid mostly presents antioxidant and anti-carcinogenic activities [28]. Rats treated with chlorogenic acid showed a significant increase in the activity of SOD, CAT, and GSH with a decrease in the TBARS level in granulation tissue compared with controls. Therefore, the antioxidant activity of chlorogenic acid may contribute to wound healing efficacy. Its wound healing promoting activity in excision wounds could also be attributed to its antioxidative effect (Figure 4). 


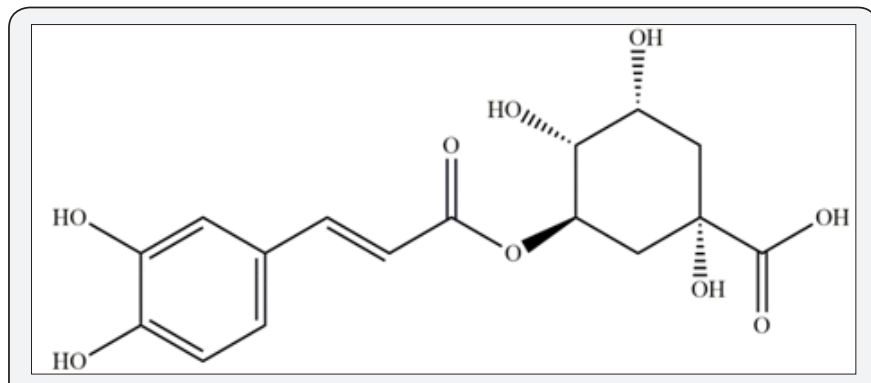

Figure 4 : Structure of Chlorogenic acid.

Since chlorogenic acid is abundant in common plants, it could be a fairly economical therapeutic agent for wound management as a healer, as well as to control abnormal healing [29]. Chlorogenic acid may present an example of an antioxidant therapeutic strategy for wound repair. Studies clarified the healing effects of chlorogenic acid supplementation on wound healing [30]. The improving wound healing activity of chlorogenic acid may be explained by the following mechanisms: enhanced capillary density and collagen production effect, antioxidant and free radical scavenger effects on oxidative parameters, and antiinflammatory effects on MMPs in wound tissues. Based on the literature, chronically excess chlorogenic acid intake may cause pro-oxidative effects on the liver, kidney, and bone marrow as side effects during long-term therapy [30].

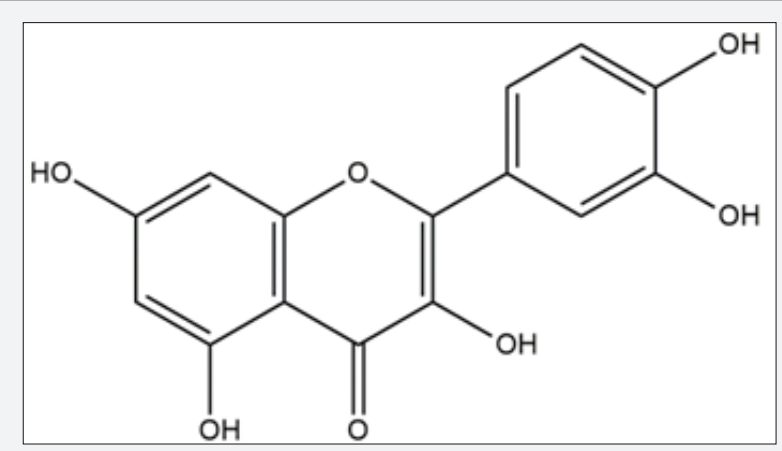

Figure 5 : Structure of Quercetin.

Quercetin: A flavonoid compound, Quercetin which is found in most of the herbs, vegetables and fruits Quercetin is reported to have the powerful anti-inflammatory, anticancer, and antioxidant supplements. Quercetin is also effective in wound healing by increasing the production of collagen and fibronectin. Quercetin may also help speed wound healing; studies have also shown that quercetin helps repair damage to nerve tissues in skin wounds. Quercetin incorporated collagenous matrix treated animal showed a better healing with an increase in proliferation of cells and wound contraction than the control group. Studies also suggested that quercetin incorporated collagen matrix could be a novel dressing material for dermal wound healing (Figure 5) [31]. It was reported that quercetin, a naturally-occurring antifibrotic agent, diminishes scar formation. Quercetin was examined using both mice and fibroblast cells on fibrosis and the wound healing rate and it was found to be decreased fibrosis, on wound healing, and relates quercetin's effects to changes in integrin expression on the surface of fibroblast cells.

The wound healing was occurred in about 14 days in the quercetin-treated group. Histopathology results revealed diminished fibrosis at the wound site in quercetin-treated animals suggest that quercetin could alter the cells' interactions with the extracellular matrix through the regulation of integrin expression to promote a decrease in fibrosis [32]. In another study, it was reported that a topical application of quercetin promotes wound healing by effectively modulating the growth factors cytokines, and cells involved in phases of wound healing. A significant time-dependent increase in wound closure was observed and also VEGF and TGF- $\beta 1$ expressions were significantly up regulated whereas TNF- $\alpha$ level was markedly reduced. IL- 10 levels and CD31 stained vessels were markedly higher and in histopathology analysis, it was found to have less inflammatory cells, increased microvessel density, more fibroblast proliferation, more regular collagen deposition and epithelialization in quercetin-treated male Wistar groups [33].

Gallic acid: Gallic acid, a plant-derived polyphenolic compound which has a wide range of therapeutic and biological activities, including anti-oxidant, anti-inflammatory, anti-oxidant, anti-microbial, anti-cancer and wound healing activities (Figure 6) [34]. It is also used as an astringent in internal haemorrhage treatment. Studies revealed that Gallic acid possesses strong antioxidant that directly upregulates the expression of antioxidant genes and also accelerated cell migration of keratinocytes and fibroblasts in both normal and hyperglycemic conditions leads to the activation of growth factors that are responsible for wound healing, such as c-Jun $\mathrm{N}$-terminal kinases (JNK), focal adhesion kinases (FAK), and extracellular signal-regulated kinases (Erk) [35]. Numerous studies reported that Gallic acid is a viable wound healing agent and a possible intervention to treat wounds ensuing from metabolic complications [35-37].

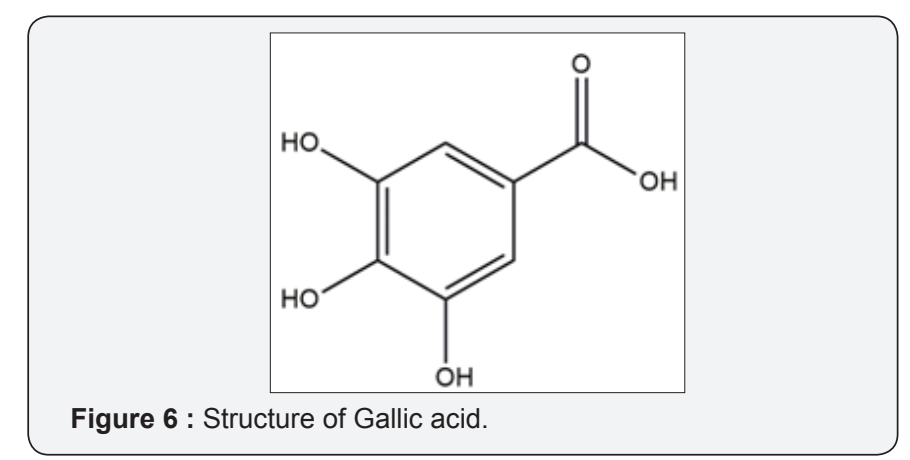

\section{Conclusion}

Many plant-derived compounds with high levels of wound healing properties, being used for the design of topical formulations and wound dressings. However, there is a lack of reports regarding the dosage level, toxicological and adverse effects of these compounds. Henceforth, a standardized protocol and clinical trials are to be followed to give more solid evidence supporting the use of pharmacologically active plant-derived compounds in treatment and management of wounds. 


\section{References}

1. Shai A, Maibach HI (2005) Wound healing and ulcers of the skin, diagnosis and therapy-the practical approach. Springer 7-15.

2. Rex Jeya Rajkumar S, Muthukumar Nadar MSA, Paulraj Mosae Selvakumar (2017) Nanotechnology in Wound Healing - A Review. Glob J Nano 3(1): 555605

3. Karapanagioti EG, Assimopoulou AN (2016) Naturally occurring wound healing agents: An evidence-based review. Curr Med Chem 23(29): 3285-3321.

4. Hosseinkhani A, Falahatzadeh M, Raoofi E, Zarshenas MM (2016) An evidence-based review on wound healing herbal remedies from reports of traditional Persian medicine. J Evid Based Complementary Altern Med 22(2): 334-343.

5. Thangapazham RL, Sharad S, Maheshwari RK (2016) Phytochemicals in Wound Healing. Adv Wound Care (New Rochelle). 5(5): 230-241.

6. Maenthaisong R, Chaiyakunapruk N, Niruntraporn S, Kongkaew C (2007) The efficacy of Aloe vera used for burn wound healing: A systematic review. Burns 33(6): 713-718.

7. Ribeiro MP, Morgado PI, Miguel SP, Coutinho P, Correia IJ (2013) Dextran-based hydrogel containing chitosan microparticles loaded with growth factors to be used in wound healing. Mater Sci Eng C 33(5): 2958-2966.

8. Cheppudira B, Fowler M, McGhee L, Greer A, Mares A, et al. (2013) Curcumin: A novel therapeutic for burn pain and wound healing. Expert Opin Investig Drugs 22(10): 1295-1303.

9. Mosae Selvakumar P, Antonyraj CA, Babu R, Dakhsinamurthy A, Manikandan N, et al. (2016) Green synthesis and antimicrobial activity of monodispersed silver nanoparticles synthesized using lemon extract. Synth React Inorg Met Org Chem 46(2): 291-294.

10. Mariselvam R, Ranjitsingh AJA, Nanthini AUR, Kalirajan K, Padmalatha C, et al. (2014) Green synthesis of silver nanoparticles from the extract of the inflorescence of Cocos nucifera (Family: Arecaceae) for enhanced antibacterial activity. Spectrochim Acta 129: 537-541.

11. Karen Kiruba K, Jesse Joel T, Lalitha S, Shabeena Merrin, Rex Jeya Rajkumar S, et al. (2016) Efficacy and Comparative Evaluation of Antimicrobial Properties from the Peel of Citrus Fruits used to Treat Diabetic Foot Ulcer. Asian Journal of Biochemical and Pharmaceutical Research 1(6): 151-166.

12. Rex Jeya Rajkumar S, Sreeraj Kuruppilakathmanikandan, Muthukumar Nadar MSA (2015) Qualitative Phytoconstituent Profile of Lobelia trigona Roxb Extracts. Int J PharmTech Res 8(10): 47-50.

13. Maquart FX, Chastang F, Simeon A, Birembaut P, Gillery P, et al. (1999) Triterpenes from Centella asiatica stimulate extracellular matrix accumulation in rat experimental wounds. Eur J Dermatol 9(4): 289296.

14. Rosen H, Blumenthal A, McCallum J (1967) Effect of asiaticoside on wound healing in the rat. Proc Soc Exp Biol Med 125(1): 279-280.

15. Liu M, Dai Y, Li Y, Luo Y, Huang F, et al. (2008) Madecassoside isolated from Centella asiatica herbs facilitates burn wound healing in mice. Planta Med 74(8): 809-815.

16. Shukla A, Rasik AM, Dhawan BN (1999) Asiaticoside-induced elevation of antioxidant levels in healing wounds. Phytother Res 13(1): 50-54.

17. Mahmood K, Zia KM, Zuber M, Salman M, Anjum MN (2015) Recent developments in curcumin and curcumin based polymeric materials for biomedical applications: A review. Int J Biol Macromol 81: 877-90.

18. Naksuriya O, Okonogi S, Schiffelers RM, Hennink WE (2014) Curcumin nanoformulations: a review of pharmaceutical properties and preclinical studies and clinical data related to cancer treatment. Biomaterials 35(10): 3365-3383.
19. Jardim KV, Joanitti GA, Azevedo RB, Parize AL (2015) Physico-chemical characterization and cytotoxicity evaluation of curcumin loaded in chitosan/chondroitin sulfate nanoparticles. Mater Sci Eng C Mater Biol Appl 56: 294-304.

20. Ghosh S, Banerjee S, Sil PC (2015) The beneficial role of curcumin on inflammation, diabetes and neurodegenerative disease: a recent update. Food Chem Toxicol 83: 111-124.

21. Ranjbar-Mohammadi M, Bahrami SH (2016) Electrospun curcumin loaded poly(-caprolactone)/gum tragacanthnanofibers for biomedical application. Int J Biol Macromol 84: 448-456.

22. Tyagi P, Singh M, Kumari H, Kumari A, Mukhopadhyay K (2015) Bactericidal activity of curcumin I is associated with damaging of bacterial membrane. PLoS One 10(3): e0121313.

23. Mun SH, Joung DK, Kim YS, Kang OH, Kim SB, et al. (2013) Synergistic antibacterial effect of curcumin against methicillin resistant Staphylococcus aureus. Phytomedicine 20(8-9): 714-718.

24. Izui S, Sekine S, Maeda K, Kuboniwa M, Takada A, et al. (2016) Antibacterial activity of curcumin against periodontopathic bacteria. J Periodontol 87(1): 83-90.

25. Wang X, Ip M, Leung AW, Yang Z, Wang P, et al. (2015) Sonodynamic action of curcumin on foodborne bacteria Bacillus cereus and Escherichia coli. Ultrasonics 62: 75-79.

26. Wang Y, Ho CT (2009) Polyphenolic chemistry of tea and coffee: a century of progress. J Agric Food Chem 57: 8109-8114.

27. Huang X (1997) Current status and prospect of the study of Lonicera japonica Thunb. Zhongguo Zhong Yao Za Zhi 22: 247-249.

28. Xu JG, Hu QP, Liu Y (2012) Antioxidant and DNA-protective activities of chlorogenic acid isomers. J Agric Food Chem 60: 11625-11630.

29. Wei-Cheng Chen, Shorong-Shii Liou, Thing-Fong Tzeng, Shiow-Ling Lee, I-Min Liu (2013) Effect of Topical Application of Chlorogenic Acid on Excision Wound Healing in Rats. Planta Med 79: 616-621.

30. Deniz Bagdas, Nihal Yasar Gul, Ayse Topal, Sibel Tas, Musa Ozgur Ozyigit, et al. (2014) Pharmacologic overview of systemic chlorogenic acid therapy on experimental wound healing. Naunyn-Schmiedeberg's Arch Pharmacol 387: 1101-1116.

31. Gomathi K, Gopinath D, Ahmed MR, Jayakumar R (2003) Quercetin incorporated collagen matrices for dermal wound healing processes in rat. Biomaterials 24(16): 2767-2772.

32. Doersch KM, Newell-Rogers MK (2017) The impact of quercetin on wound healing relates to changes in $\alpha \mathrm{V}$ and $\beta 1$ integrin expression. Exp Biol Med 242(14): 1424-1431.

33. Gopalakrishnan A, Ram M, Kumawat S, Tandan SK, Kumar D (2016) Quercetin accelerated cutaneous wound healing in rats by increasing levels of VEGF and TGF- $\beta 1$. Indian J Exp Biol 54(3): 187-195.

34. Bachrach U, Wang YC (2002) Cancer therapy and prevention by green tea: Role of ornithine decarboxylase. Amino Acids 22(1): 1-13.

35. Yang DJ, Moh SH, Son DH, You S, Kinyua AW, et al. (2016) Gallic acid promotes wound healing in normal and hyperglucidic conditions. Molecules 21(7): 899.

36. Kroes BH, van den Berg AJ, Quarles van Ufford HC van Dijk H, Labadie RP (1992) Anti-inflammatory activity of gallic acid. Planta Med 58(6): 499-504.

37. Kubo I, Xiao P, Fujita K (2001) Antifungal activity of octyl gallate: Structural criteria and mode of action. Bioorg Med Chem Lett 11(3): 347-350. 
CC (i) This work is licensed under Creative

DOI: 10.19080/OMCIJ.2018.05.555653

\section{Your next submission with Juniper Publishers} will reach you the below assets

- Quality Editorial service

- Swift Peer Review

- Reprints availability

- E-prints Service

- Manuscript Podcast for convenient understanding

- Global attainment for your research

- Manuscript accessibility in different formats ( Pdf, E-pub, Full Text, Audio)

- Unceasing customer service

Track the below URL for one-step submission https://juniperpublishers.com/online-submission.php 